\title{
Ruxolitinib for the treatment of myelofibrosis: its clinical potential
}

This article was published in the following Dove Press journal:

Therapeutics and Clinical Risk Management

29 February 2012

Number of times this article has been viewed

\section{Alen Ostojic' \\ Radovan Vrhovac' \\ Srdan Verstovsek ${ }^{2}$ \\ 'Division of Hematology, Department of Internal Medicine, University Hospital Center Zagreb, Zagreb, Croatia; ${ }^{2}$ Department of Leukemia, University of Texas, MD Anderson Cancer Center, Houston, TX, USA}

Correspondence: Srdan Verstovsek UT MD Anderson Cancer Center, Department of Leukemia, Unit 428, I5 I 5 Holcombe Blvd, Houston, TX 77030, USA

Tel + I 7137453429

Fax +I 7137944297

Email sverstov@mdanderson.org

\begin{abstract}
Ruxolitinib is an orally bioavailable, selective Janus kinase (JAK) 1 and 2 inhibitor approved for the treatment of myelofibrosis (MF), a bone marrow disease in which the JAK pathway is dysregulated, leading to impaired hematopoiesis and immune function. By inhibiting JAK1 and JAK2, ruxolitinib modulates cytokine-stimulated intracellular signaling. In a phase II clinical trial in patients with MF, ruxolitinib recipients exhibited durable reductions in spleen size, reductions in circulating pro-inflammatory cytokines, improvements in physical activity, weight gain, and alleviation of symptoms (including constitutional symptoms) in patients with and without JAK2 mutation. These findings were confirmed by two phase III clinical MF studies, in which a greater proportion of ruxolitinib recipients achieved a spleen volume reduction of $\geq 35 \%$ from baseline at week 24 , compared with placebo in one study ( $41.9 \%$ versus $0.7 \% ; P<0.0001)$ and with best available therapy in the other $(31.9 \%$ versus $0 \%$; $P<0.0001)$. Alleviation of MF symptoms and improvements in quality of life were also significantly greater in ruxolitinib recipients. Overall survival of patients treated with ruxolitinib was significantly longer than of those receiving the placebo. Owing to risks of potentially serious adverse effects, eg, myelosuppression, ruxolitinib should be used under close physician supervision. Longer follow-up of the phase III MF studies is needed to reach firm conclusions regarding ruxolitinib's capacity to modify the natural disease course.
\end{abstract}

Keywords: myelofibrosis, JAK2 inhibitor, ruxolitinib

\section{Introduction}

Myelofibrosis (MF) is a bone marrow disease characterized by excessive production of reticulin and collagen fibers. Although fibrosis can be the outcome of numerous hematologic and nonhematologic conditions, ${ }^{1}$ the term MF is commonly used in reference either to primary $\mathrm{MF}(\mathrm{PMF})^{2}$ or to the similar disorders evolving from the two other classic Philadelphia-chromosome-negative myeloproliferative neoplasms: polycythemia vera (post-PV MF) and essential thrombocythemia (post-ET MF). ${ }^{3}$ According to epidemiological studies, ${ }^{4-9}$ the incidence of PMF may be as high as 1.5 per 100,000. Other studies ${ }^{10-14}$ show that by the end of the second decade after PV or ET diagnosis, up to $10 \%-15 \%$ of cases may transform to secondary MF.

In $\mathrm{MF}$, the fibrotic changes appear to be cytokine-stimulated reactions sustained by multilineage clonal cellular proliferation. ${ }^{15-21}$ The clinical signs of MF include splenomegaly due to extramedullary hematopoiesis; leukocytosis and thrombocytosis, with predisposition to thrombotic events, due to clonal cellular proliferation affecting mainly megakaryocytes and granulocytes; cytopenias, a later finding that worsens with the progression of fibrosis; and constitutional symptoms (eg, fatigue, weight 
loss, low-grade fever, night sweats), most likely induced by abnormal levels of circulating cytokines.

In the past decade, the role of Janus kinases (JAKs) in intracellular pathways has claimed the attention of many myeloproliferative neoplasm researchers. JAKs are nonreceptor tyrosine kinases that mediate the transmission of cytokine- and growth-factor-induced intracellular signals (Figure 1). About $50 \%$ of patients with PMF present with the JAK2 ${ }^{\mathrm{V} 617 \mathrm{~F}}$ gain-of-function mutation, resulting in a constitutively activated JAK-signal transducer and activator of transcription (JAK-STAT) pathway. ${ }^{22,23}$ In turn, the activated
JAK-STAT pathway promotes the transcription of numerous genes, eg, for cytokines, fibrogenic factors, and angiogenic factors, among a broad variety of pro-proliferative and anti-apoptotic gene products. ${ }^{24-29}$ Excessive production of pro-inflammatory cytokines may itself contribute to JAKSTAT activation, ${ }^{30}$ creating a vicious cycle. Among patients with $\mathrm{MF}$, about $5 \%$ are JAK2 ${ }^{\mathrm{V} 617 \mathrm{~F}}$-negative but instead have a gain-of-function mutation in the thrombopoietin receptor gene (MPL ${ }^{\mathrm{W} 15 \mathrm{~L}}$ mutation), resulting in cytokine-independent JAK-STAT activation. ${ }^{31,32}$ Another small group of patients with MF have neither of these mutations but carry other

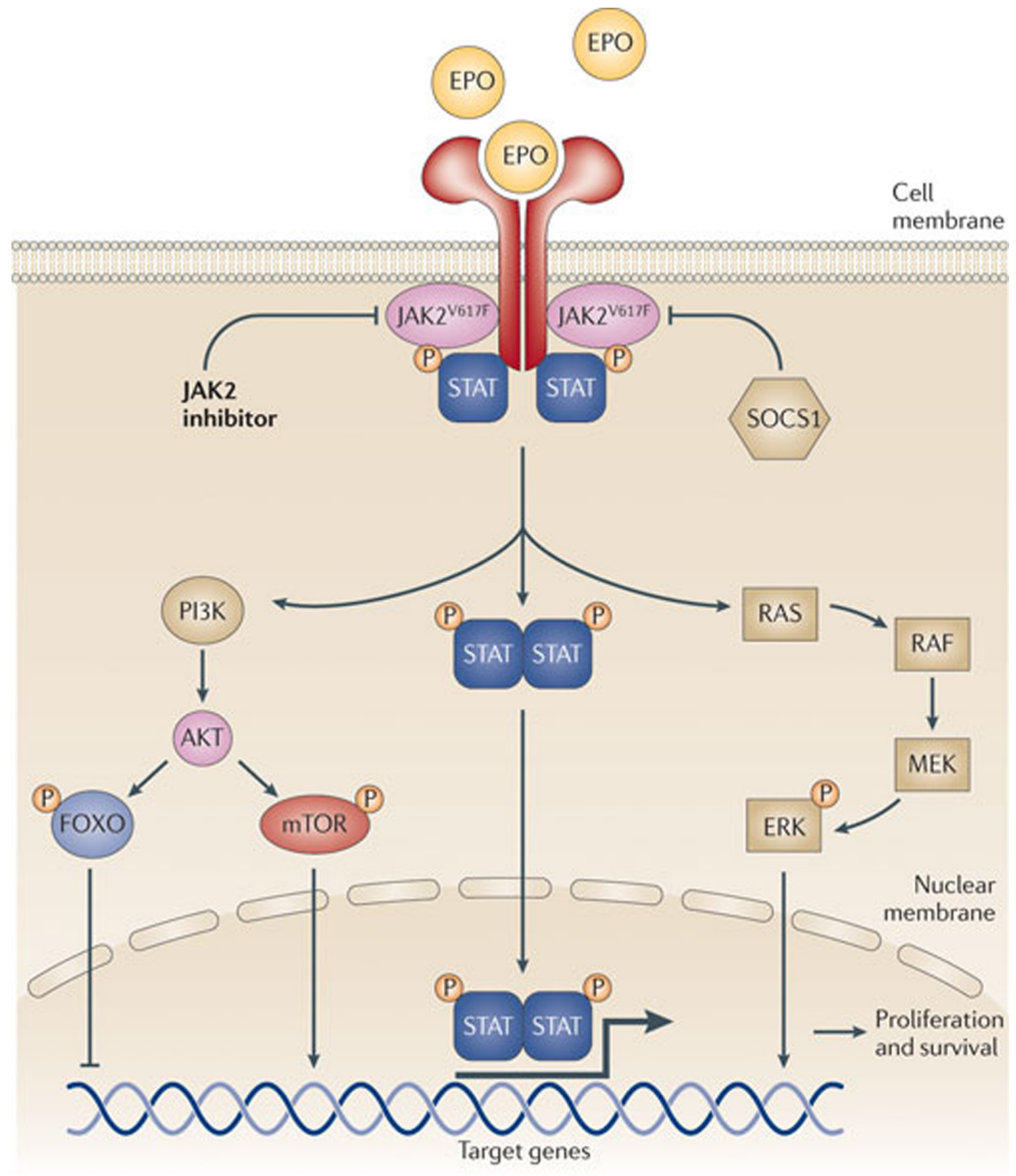

Nature Reviews | Drug Discovery

Figure I The JAK-STAT intracellular signaling pathway in myelofibrosis. Copyright @ 20II, Nature Publishing Group. Reproduced with permission from Quintàs-Cardama A, Kantarjian H, Cortes J, Verstovsek S. Janus kinase inhibitors for the treatment of myeloproliferative neoplasias and beyond. Nat Rev Drug Discov. 20I I; I0(2): I 27-I40.60 
mutations (eg, in lymphocyte adaptor protein ${ }^{33}$ or in the receptor adaptor protein CBL) $)^{34}$ associated with constitutive JAK2 activation. Moreover, patients with MF in the absence of any identified mutation often exhibit JAK2 overactivity. JAK1 also plays a role in MF: a recent study ${ }^{30}$ demonstrated JAK1 hyperactivity in MF patients, most likely as a consequence of cytokine hyperstimulation. Collectively, these data implicate JAK1 and JAK2 as important pieces in the puzzle posed by the molecular pathogenesis of MF.

Currently, the only potentially curative treatment for MF is allogeneic hematopoietic stem cell transplantation, an option traditionally feasible only for a small subgroup of patients, the younger and physically fit, although new reports suggest its utility in the older patients as well. ${ }^{35,36}$ Other treatment modalities (eg, hydroxyurea, anagrelide, splenectomy or splenic irradiation, lenalidomide or thalidomide with or without corticosteroids, transfusions, danazol, androgens) are only palliative and without a substantial influence on survival. ${ }^{37-53}$ Patients often die from bone marrow failure accompanied by systemic infection or fatal hemorrhage. ${ }^{20,54,55}$ However, with the discovery of the JAK2 ${ }^{\mathrm{V} 617 \mathrm{~F}}$ mutation, ${ }^{56-59}$ JAK2 emerged as a potential target for treatment, and several small-molecule, ATP-competitive JAK2 inhibitors were developed (SAR302503 [TG101348], lestaurtinib [CEP-701], XL019, SB1518, CYT387, AZD1480, and ruxolitinib). ${ }^{60-63}$ Ruxolitinib (formerly known as INCB018424) is the first and currently the only JAK inhibitor approved by the US Food and Drug Administration or any other regulatory agency for treatment of patients with $\mathrm{MF} ;{ }^{64}$ and clinical development of several JAK inhibitors (SAR302503 [TG101348], CYT387, and LY278544) is ongoing. Although not as developed as ruxolitinib, available data on the efficacy of the other JAK2 inhibitors suggests similar profiles, mainly reduction in the size of enlarged organs (splenomegaly and hepatomegaly) and elimination of MF-related symptoms. The differences among them so far are mainly seen in relation to their toxicity profiles, eg, a degree of myelosuppression, gastrointestinal and/or neurological side effects.

\section{Preclinical studies of ruxolitinib}

Ruxolitinib phosphate (Figure 2) is an orally administered ATP-competitive cyclopentylpropionitrile derivative. In preclinical studies, it showed inhibitory activity in vitro mainly against JAK1 $\left(\mathrm{IC}_{50}=3.3 \mathrm{nM}\right)$ and JAK2 $\left(\mathrm{IC}_{50}=2.8 \mathrm{nM}\right) .{ }^{30}$ Moderate to minimal inhibitory activity was observed against nonreceptor tyrosine kinase TYK2 (half-maximal inhibitory concentration $\left[\mathrm{IC}_{50}\right]=19 \mathrm{nM}$ ) and against JAK3 $\left(\mathrm{IC}_{50}=428 \mathrm{nM}\right)$, as well as minimal inhibitory

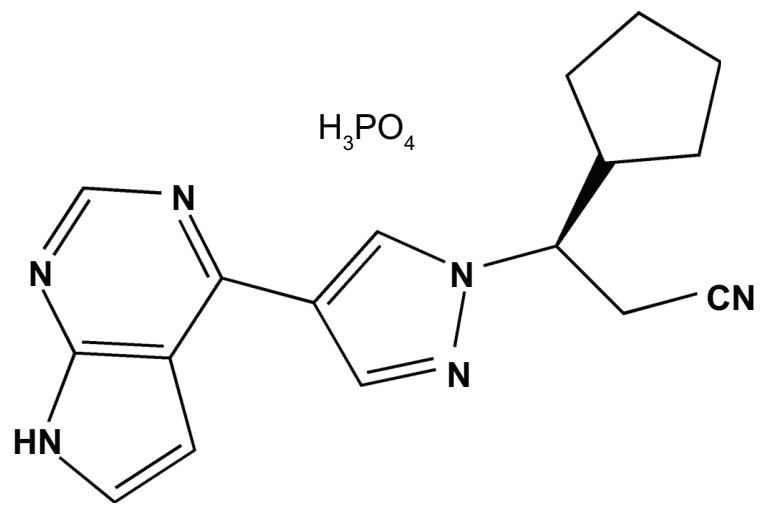

Figure 2 Ruxolitinib-phosphate, a chemical structure of orally available Janus kinase $I$ and 2 inhibitor.

activity against multiple other kinases at concentrations about 100 -fold higher than the $\mathrm{IC}_{50}$ for JAK $1 / 2 .{ }^{30}$ Selectivity against JAK1/2 was confirmed by measurements of STAT activity in a cytokine-stimulated whole-blood assay. ${ }^{30}$

In an engineered cell system containing growthfactor-independent JAK $2^{\mathrm{V} 617 \mathrm{~F}}$-expressing $\mathrm{Ba} / \mathrm{F} 3$ cells (Ba/F3-EpoR-JAK2 $\left.{ }^{\mathrm{V} 617 \mathrm{~F}}\right)$, ruxolitinib demonstrated a dose-dependent reduction of JAK2-mediated downstream phosphorylated proteins with no change in their total levels, ${ }^{30}$ suggesting that ruxolitinib exerts its effect through achievement of reduced levels of phosphorylated (active) forms. A similar effect was observed in the HEL cell line. ${ }^{30}$ In these cell lines and in cells from mononuclear PV patients, ruxolitinib demonstrated antiproliferative and proapoptotic effects. ${ }^{30}$ Analogous effects were not observed on BCRABL-1 signaling or in a cell line expressing an activating mutation in c-KIT. ${ }^{30}$ The effects of ruxolitinib were attenuated when cells expressing JAK $2^{\mathrm{V} 617 \mathrm{~F}}$ were cocultured with primary or immortalized human bone marrow mesenchymal

Table I Examples of strong cytochrome P450 3A4 inhibitors with potential influence on the pharmacokinetics of coadministered ruxolitinib ${ }^{71,72}$

\section{Drug}

Ketoconazole ${ }^{a}$

Itraconazole ${ }^{\mathrm{a}}$

Posaconazole

Voriconazole

Clarithromycin

Telithromycin

Atazanavir

Indinavir

Nelfinavir

Ritonavir

Saquinavir

Nefazodone

Note: a ${ }^{\circ}$ bserved interaction. ${ }^{70}$ 
Table 2 Observed incidence of thrombocytopenia and anemia in clinical trials of ruxolitinib

\begin{tabular}{|c|c|c|c|c|c|}
\hline \multirow[t]{2}{*}{ Treatment group } & \multirow{2}{*}{$\frac{\text { Phase I/II trial }{ }^{73}}{\text { Ruxolitinib }}$} & \multicolumn{2}{|c|}{ Phase III COMFORT-I trial ${ }^{75,76}$} & \multicolumn{2}{|c|}{ Phase III COMFORT-II trial ${ }^{74}$} \\
\hline & & Ruxolitinib & Placebo & Ruxolitinib & Best available therapy \\
\hline $\mathrm{nn}$ & $82^{\mathrm{a}}$ & 155 & 154 & 146 & 73 \\
\hline Thrombocytopenia grade 3 or $4^{b}$ & $3 \%-29 \%$ & $12.9 \%$ & $1.3 \%$ & $8.3 \%$ & $7.2 \%$ \\
\hline Anemia grade 3 or $4^{b}$ & $8 \%-27 \%$ & $45.2 \%$ & $19.2 \%$ & $42.4 \%$ & $31.4 \%$ \\
\hline
\end{tabular}

Notes: ancludes only patients on $15 \mathrm{mg} /$ bid and $25 \mathrm{mg} /$ bid regimens; ${ }^{b}$ According to Common Terminology Criteria for Adverse Events, version 3.0 .

Abbreviation: COMFORT, Controlled Myelofibrosis Study with Oral Janus kinase I and 2 Inhibitor Treatment.

stromal cells, probably owing to paracrine activity of the mesenchymal stromal cells. ${ }^{65}$ Several point mutations identified on a $\mathrm{Ba} / \mathrm{F} 3$ cell line expressing JAK2 ${ }^{\mathrm{V} 617 \mathrm{~F}}$ may be a cause of resistance to ruxolitinib in experimental in vitro systems. ${ }^{66}$

Evidence from preclinical studies in mouse models confirmed JAK1 and JAK2 as targets for MF therapy. $\mathrm{Balb} / \mathrm{c}$ mice injected with $\mathrm{Ba} / \mathrm{F} 3-\mathrm{EpoR}-J A K 2^{\mathrm{V} 617 \mathrm{~F}}$ cells had significant reductions in spleen size, tumor burden, and circulating cytokines when treated with ruxolitinib, compared with vehicle treatment. ${ }^{30}$ In the ruxolitinib-treated mice, the histomorphology of affected organs was normalized, and anemia and lymphopenia were not detected. More than $90 \%$ of ruxolitinib-treated mice survived, while by the 22nd day of treatment, more than $90 \%$ of vehicle-treated mice died.

\section{Pharmacokinetics and metabolism}

The pharmacokinetics and metabolism of ruxolitinib were established in early studies in healthy volunteers who received single doses of $25 \mathrm{mg}^{67}$ or single or multiple ascending doses of $5 \mathrm{mg}$ to as much as $200 \mathrm{mg} .{ }^{68}$ After a single oral dose, $>95 \%$ of the drug is absorbed, and $>97 \%$ of the absorbed drug becomes bound to plasma proteins. Plasma concentrations peak 1-3 hours after administration, with monophasic or biphasic decline. The terminal half-life is 2-3 hours. Administration of doses of up to $200 \mathrm{mg}$ demonstrated dose-proportional exposure.

Ruxolitinib is metabolized predominantly in the liver, as a substrate of cytochrome P450 3A4 (CYP3A4), and its metabolites are mainly excreted in urine..$^{67,68}$ There is no evidence of accumulation of either ruxolitinib or its metabolites ${ }^{67}$ Factors that may influence the pharmacokinetics of ruxolitinib have been evaluated. A high-fat meal reduced the maximum plasma concentration by $24 \%$, but had no substantial influence on bioavailability. ${ }^{68}$ Because of the routes by which ruxolitinib is metabolized and excreted, exposure may be increased in patients with impaired renal or hepatic function. ${ }^{69,70}$ When coadministered with rifampin (a CYP3A4 inducer), or erythromycin (a moderate
CYP3A4 inhibitor), no changes in ruxolitinib pharmacokinetics were observed in healthy subjects. ${ }^{71}$ However, in healthy subjects who received ruxolitinib concomitantly with ketoconazole (a strong CYP3A4 inhibitor), the area under the curve increased by $91 \%$ and the half-life increased from 3.7 to 6.0 hours. There is a possibility of similar effects when ruxolitinib is coadministered with drugs that are strong inhibitors of CYP3A4 (Table 1). . $2,73^{2}$

\section{Safety across clinical trials}

In healthy volunteers and in patients with MF, myelosuppression, and in particular thrombocytopenia, was the dose-limiting toxicity of ruxolitinib. The maximum tolerated dose was established as $25 \mathrm{mg}$ twice daily (bid) and $100 \mathrm{mg}$ once daily (qd). ${ }^{68,74}$ One healthy volunteer receiving a ruxolitinib dose of $50 \mathrm{mg} /$ bid developed highgrade neutropenia and recovered 12 days after ruxolitinib discontinuation. ${ }^{68}$ In phase I/II and III clinical trials in patients with MF, the most common hematologic adverse effects were thrombocytopenia and anemia (Table 2). ${ }^{7-78}$ Myelosuppression was dose-dependent and was not a frequent reason for withdrawal. ${ }^{7-76}$ Dose-dependent myelosuppression was not observed in a study of healthy volunteers. ${ }^{68}$ In the blinded, placebo-controlled phase III trial, the most frequent nonhematologic adverse events reported more commonly for ruxolitinib treatment than for placebo were ecchymosis, dizziness, and fatigue (mostly grade 1 or 2). Given the mechanism of action of ruxolitinib (JAK1/JAK2 inhibition), immunosuppression may be a possible adverse event; however, this was not observed to an appreciable extent in the clinical trials so far.

In a phase I/II clinical trial, investigators described clinical symptoms and signs suggesting development of systemic inflammatory response syndrome in two patients (1.3\%) following sudden cessation of ruxolitinib. ${ }^{74} \mathrm{~A}$ similar reaction was not described among patients in two phase III clinical trials. ${ }^{75-77}$ Nevertheless, recently published phase I/II data from one center ${ }^{78,79}$ describe similar effects of abrupt cessation in four patients, and 2 weeks after cessation a 
fifth patient developed a syndrome similar to disseminated intravascular coagulation with sequential severe polyarticular arthritis. Cytokine-rebound phenomena were suggested as mechanisms leading to "ruxolitinib discontinuation syndrome." Apart from this one-center experience, such events have not been observed by other investigators in any other study ( $\sim 170$ clinical centers). However, to avoid any possibility of such complications, it is advisable to taper the dose when discontinuing ruxolitinib. ${ }^{78,79}$

\section{Efficacy in the phase I/II clinical trial of ruxolitinib in MF}

A phase I/II clinical trial ${ }^{74}$ of open-label ruxolitinib in MF (INCB018424-251; ClinicalTrials.gov, NCT00509899) was conducted at two United States centers: the MD Anderson Cancer Center in Houston, Texas and the Mayo Clinic in Rochester, Minnesota. In all, 153 patients (PMF 53\%, post-PV MF $32 \%$, and post-ET MF 15\%) were enrolled, with a median age of 65 years (range, $40-84$ years). On the Lille scoring system, ${ }^{80} 65 \%$ of patients were at high risk, $28 \%$ at intermediate- 2 risk, $7 \%$ at undetermined risk, and $82 \%$ were JAK2 ${ }^{\mathrm{V} 617 \mathrm{~F}}$-positive. In phase I of the study, a maximum tolerated dose and dose-limiting toxicity were identified.

In phase II, several dosing regimens, all below the maximum tolerated dose, were investigated. Among them, $15 \mathrm{mg} / \mathrm{bid}$ and $25 \mathrm{mg} /$ bid regimens were identified as the most appropriate for optimal efficacy and minimal adverse effects. In $52 \%$ and $49 \%$ of the patients on these regimens (15 mg/bid and $25 \mathrm{mg} / \mathrm{bid}$, respectively), ruxolitinib reduced palpable splenomegaly by $\geq 50 \%$ from baseline (the study's predefined measure of clinical improvement) after three cycles of treatment (one cycle $=4$ weeks of daily ruxolitinib). Among patients exhibiting this response, the response was maintained after 12 months of treatment in $73 \%$ of those on $15 \mathrm{mg} / \mathrm{bid}$ and $78 \%$ of those on $25 \mathrm{mg} / \mathrm{bid}$. The $15 \mathrm{mg} / \mathrm{bid}$ regimen was associated with a lower incidence of grade 3 or 4 thrombocytopenia. In a subset of 24 patients in the $15 \mathrm{mg} / \mathrm{bid}$ group, change in spleen volume was evaluated by magnetic resonance imaging (MRI); the median reduction after six cycles of treatment was 33\%, corresponding to a median $52 \%$ reduction in palpable spleen length. In the same MRI substudy, hepatomegaly decreased by $14 \%$ in six patients with hepatomegaly at baseline.

Patients also demonstrated improvement in other measures of disease burden. On a 6-minute walk test, ${ }^{81}$ as performed in 27 patients after 1, 3, and 6 months of treatment, median distances walked were 34,57 , and $71 \mathrm{~m}$, respectively. Moreover, after a year of treatment, patients on $15 \mathrm{mg} / \mathrm{bid}$ and
$25 \mathrm{mg} /$ bid regimens gained weight: a median 9.4 and $7.1 \mathrm{~kg}$, respectively. Ruxolitinib recipients with a body mass index in the lowest quartile at baseline had the most prominent weight gain. In general, improvements in performance status were maintained with therapy.

Ruxolitinib treatment also led to decreases in peripheral blood cell counts, including CD34-positive cells. In addition, peripheral blood cytokine levels (of interleukin-1 and tumor necrosis factor-alfa) decreased in association with improvement of symptoms, while plasma levels of leptin and erythropoietin increased. Thirty-four patients were available for evaluation of JAK $2^{\mathrm{V} 617 \mathrm{~F}}$ allele burden reduction; the mean maximal suppression was modest (13\% from baseline). However, a dose-dependent reduction of constitutively phosphorylated STAT3 and STAT5 was observed.

Recently, the two centers participating in this phase I/II clinical trial have published separate reports ${ }^{78,82,83}$ of their long-term experience in the treatment of patients with MF. For 51 ruxolitinib-treated patients enrolled in the trial between October 2007 and February 2009 inclusive, the Mayo Clinic in Rochester reported a high discontinuation rate: $51 \%, 72 \%$, and $89 \%$ at 1,2 , and 3 years, respectively. ${ }^{78}$ As of October 2011, 18 patients (35\%) had died and five patients $(10 \%)$ had developed transformation to leukemia. Survival rate showed no significant difference between the ruxolitinib recipients and a cohort of 410 recipients of standard PMF treatment at their center during the past decade $(P=0.43)$.

In contrast, the MD Anderson Cancer Center reported that of 107 patients enrolled in the phase I/II trial, 58 (54\%) were still receiving ruxolitinib at a median of 32 months. ${ }^{82}$ As of December 2011, 33 patients (31\%) had died, 19 of them off-study and none for therapy-related reasons, and nine patients $(8 \%)$ had developed transformation to leukemia, four of them off-study. By log-rank analysis, the survival of patients receiving ruxolitinib was significantly longer than in a historical cohort of 310 patients treated with standard or investigational therapy who would have met the phase I/II trial enrollment criteria (hazard ratio $=0.61,95 \% \mathrm{CI}: 0.41-0.89 ; P=0.02) .{ }^{83}$ Survival of high-risk ruxolitinib recipients (of whom 21 of 63 , or $33 \%$, died) was also significantly longer $(P=0.006)$ than that of high-risk patients from the control group (of whom 112 of 165 , or $68 \%$, died). Patients continue to be followed. The outcome differences between the cohorts at the two centers are possibly related to the inferior efficacy of therapy at the Mayo Clinic in Rochester due to lower dosage and shorter duration (higher discontinuation rate) of therapy. ${ }^{83}$ 


\section{Phase III clinical trials of ruxolitinib in MF}

Two phase III clinical trials, the Controlled Myelofibrosis Study with Oral JAK1/JAK2 Inhibitor Treatment I and II (COMFORT- ${ }^{76,77}$ AND COMFORT-II $;{ }^{75}$ ClinicalTrials.gov, NCT00952289 and NCT00934544, respectively), have been conducted and are still ongoing.

COMFORT-I is a double-blind, placebo-controlled study that enrolled 309 adults with MF in the United States, Canada, and Australia. Patients were randomized (1:1) to receive ruxolitinib or placebo. Based on baseline peripheral blood platelet count (Plt), the ruxolitinib was initiated at $15 \mathrm{mg} / \mathrm{bid}$ $\left(\mathrm{Plt}=100-200 \times 10^{9} / \mathrm{L}\right)$ or $20 \mathrm{mg} / \mathrm{bid}\left(\mathrm{Plt}>200 \times 10^{9} / \mathrm{L}\right)$. Dose adjustment was allowed in accordance with efficacy and safety observations during the study, as defined by the protocol. At week $24,41.9 \%$ and $0.7 \%$ of patients receiving ruxolitinib and placebo, respectively, achieved a spleen volume reduction $\geq 35 \%$ from baseline (the primary endpoint), as evaluated by MRI or computed tomography. ${ }^{76,77}$ Changes in symptoms were measured by the modified Myelofibrosis Symptom Assessment Form v2.0 Total Symptom Score (TSS) ${ }^{84}$ In the ruxolitinib and placebo arms, respectively, $45.9 \%$ and $5.3 \%(P<0.0001)$ of patients had at least a $50 \%$ improvement in TSS; mean TSS improved by $46.1 \%$ in the ruxolitinib and worsened by $41.8 \%$ in the placebo group. All individual symptoms assessed in the Myelofibrosis Symptom Assessment Form improved in ruxolitinib recipients and worsened in placebo recipients. ${ }^{76,77}$ The same trends of improvements in TSS and reductions in spleen volume were observed in subgroup analyses based on MF type (PMF, post-PV MF, or post-ET MF), IPSS risk group (intermediate- 2 or high), age ( $\leq 65$ or $>65$ years), JAK2 $2^{\mathrm{V} 617 \mathrm{~F}}$ mutation status (presence or absence), baseline palpable spleen length $(\leq 10$ or $>10 \mathrm{~cm}$ ), and baseline hemoglobin level $(\geq 10$ or $<10 \mathrm{~g} / \mathrm{dL}) .{ }^{85}$

Quality of life (QoL) was measured by European Organization for Research and Treatment of Cancer Quality of Life Questionnaire (EORTC QLQ-C30). ${ }^{86}$ Improvements in QoL correlated with the alleviation of symptoms. ${ }^{76-87}$ Patients with spleen size reductions of at least $10 \%$ realized meaningful improvements in symptoms and QoL. ${ }^{87,88}$

At a median follow-up of 52 weeks in the ruxolitinib and 51 weeks in the placebo arm, there had been 13 and 24 deaths, respectively, with a hazard ratio of 0.50 (95\% CI: $0.25-0.98$; $P=0.04$ ), which provided evidence that ruxolitinib may prolong the life of patients with advanced MF. ${ }^{85}$

COMFORT-II is a double-blind phase III study of 219 patients with MF, conducted in nine European countries.
Patients were randomized (2:1) to ruxolitinib or best available therapy (BAT). The ruxolitinib dose was $15 \mathrm{mg} / \mathrm{bid}$ or $20 \mathrm{mg} /$ bid, based on the same Plt values as in COMFORT-I, and was subject to adjustment within the range of $5 \mathrm{mg} / \mathrm{bid}$ to $25 \mathrm{mg} / \mathrm{bid}$. The BAT could be oral, parenteral, or no therapy. Spleen volume reductions of $\geq 35 \%$ (by MRI or computed tomography) at weeks 48 and 24 were the primary and key secondary endpoints, respectively. The primary endpoint was reached by $28.5 \%$ of ruxolitinib and $0 \%$ of BAT recipients $(P<0.0001)$, and the key secondary endpoint by $31.9 \%$ and $0 \%(P<0.0001) .{ }^{75}$ Response rates were also higher for ruxolitinib than for BAT in subgroups based on JAK2 $2^{\mathrm{V} 617 \mathrm{~F}}$ mutational status, risk group, MF type, hydroxyurea pretreatment, baseline spleen size or volume, age, and sex. ${ }^{89}$

Symptoms measured by the EORTC QLQ-C30 showed significant improvements in the ruxolitinib group, starting at week 8 , with continued improvement through week 48 versus BAT $(P<0.05) .{ }^{90}$ Similarly, mean subscores in the Functional Assessment of Cancer Therapy-Lymphoma System (FACT-LymS) ${ }^{91}$ improved with ruxolitinib treatment. No significant difference was found between risk-based subgroups of ruxolitinib recipients.

A post-hoc comparison of the COMFORT-I placebo and COMFORT-II BAT groups showed no significant difference in symptoms and QoL. In the placebo group, median spleen volume increased at week 24 by $8.5 \%$ (range, $-46.4 \%$ to $+48.8 \%$ ) and in the BAT group by $5.1 \%$ (range, $-33.3 \%$ to $+29.7 \%$ ). ${ }^{92}$

\section{Conclusion}

In clinical trials, ruxolitinib alleviated the burdensome manifestations of MF, namely splenomegaly and disease core symptoms. Patients experienced reductions in spleen size, decreases in circulating pro-inflammatory cytokines, increases in weight, and substantial improvements in symptoms and QoL. Based on the efficacy and tolerability reported in clinical trials, ruxolitinib became the first drug approved by the US Food and Drug Administration, in mid-November 2011, for the treatment of MF, and now has an important place among available treatment options. The reported data suggests that its effects are independent of patient characteristics including age, MF subtype, risk group, JAK2 $2^{\mathrm{V} 617 \mathrm{~F}}$ mutation status, baseline palpable spleen length, and baseline hemoglobin level. Although data from the COMFORT-I phase III clinical trial provides evidence that ruxolitinib prolongs the life of patients with advanced MF, ruxolitinib does not have a curative potential in the disease. On the other hand, ruxolitinib seems 
to offer significant and clinically meaningful benefit over other treatment modalities currently used when allogeneic hematopoietic stem cell transplantation is not an option. Also, it may become useful in pretreating patients deemed unfit for allogeneic hematopoietic stem cell transplantation, perhaps aiding them in becoming clinically fit for the transplant procedure. However, this would have to be proved in clinical trials. Due to potentially serious adverse effects, ruxolitinib should be used under close supervision of a physician. Follow-up data from the ruxolitinib phase III clinical trials, especially concerning long-term effects and survival, are needed to draw any stronger conclusions about its enduring benefits in MF. The next wave of clinical studies will explore the combination strategies in MF, by combining ruxolitinib with other active agents in this disease, eg, lenalidomide, danazol, erythropoietin, interferon, and others, with a goal to bring additional benefits to the JAK2 inhibitor therapy, like improvement in blood cell count and decrease in bone marrow fibrosis.

\section{Disclosure}

Professor S. Verstovsek has received research support from Incyte for the conduct of clinical studies. The other authors state no conflicts of interest.

\section{References}

1. Kuter DJ, Bain B, Mufti G, Bagg A, Hasserjian RP. Bone marrow fibrosis: pathophysiology and clinical significance of increased bone marrow stromal fibres. Br J Haematol. 2007;139(3):351-362.

2. Vardiman JW, Thiele J, Arber DA, et al. The 2008 revision of the World Health Organization (WHO) classification of myeloid neoplasms and acute leukemia: rationale and important changes. Blood. 2009;114(5):937-951.

3. Barosi G, Mesa RA, Thiele J, et al. Proposed criteria for the diagnosis of post-polycythemia vera and post-essential thrombocythemia myelofibrosis: a consensus statement from the International Working Group for Myelofibrosis Research and Treatment. Leukemia. 2008;22(2):437-438.

4. Chaiter Y, Brenner B, Aghai E, Tatarsky I. High incidence of myeloproliferative disorders in Ashkenazi Jews in northern Israel. Leuk Lymphoma. 1992;7(3):251-255.

5. Dougan LE, Matthews ML, Armstrong BK. The effect of diagnostic review on the estimated incidence of lymphatic and hematopoietic neoplasms in Western Australia. Cancer. 1981;48(3):866-872.

6. Johansson P, Kutti J, Andreasson B, et al. Trends in the incidence of chronic Philadelphia chromosome negative ( $\mathrm{Ph}-)$ myeloproliferative disorders in the city of Goteborg, Sweden, during 1983-1999. J Intern Med. 2004;256(2):161-165.

7. Kutti J, Ridell B. Epidemiology of the myeloproliferative disorders: essential thrombocythaemia, polycythaemia vera and idiopathic myelofibrosis. Pathol Biol (Paris). 2001;49(2):164-166.

8. Mesa RA, Silverstein MN, Jacobsen SJ, Wollan PC, Tefferi A. Population-based incidence and survival figures in essential thrombocythemia and agnogenic myeloid metaplasia: an Olmsted County Study, 1976-1995. Am J Hematol. 1999;61(1):10-15.

9. Woodliff HJ, Dougan L. Myelofibrosis in Western Australia: an epidemiological study of 29 cases. Med J Aust. 1976;1(15):523-525.
10. Alvarez-Larrán A, Cervantes F, Bellosillo B, et al. Essential thrombocythemia in young individuals: frequency and risk factors for vascular events and evolution to myelofibrosis in 126 patients. Leukemia. 2007;21(6):1218-1223.

11. Najean Y, Rain JD, Dresch C, et al. Risk of leukaemia, carcinoma, and myelofibrosis in $32 \mathrm{P}$ - or chemotherapy-treated patients with polycythaemia vera: a prospective analysis of 682 cases. The "French Cooperative Group for the Study of Polycythaemias." Leuk Lymphoma. 1996;22(Suppl 1):111-119.

12. Passamonti F, Rumi E, Arcaini L, et al. Prognostic factors for thrombosis, myelofibrosis, and leukemia in essential thrombocythemia: a study of 605 patients. Haematologica. 2008;93(11):1645-1651.

13. Randi ML, Barbone E, Fabris F, Varotto L, Macri C, Girolami A. Post-polycythemia myeloid metaplasia: experience with a large cohort of patients. J Med. 1994;25(6):363-369.

14. Wolanskyj AP, Schwager SM, McClure RF, Larson DR, Tefferi A. Essential thrombocythemia beyond the first decade: life expectancy, long-term complication rates, and prognostic factors. Mayo Clin Proc. 2006;81(2):159-166.

15. Vannucchi AM, Bianchi L, Cellai C, et al. Development of myelofibrosis in mice genetically impaired for GATA-1 expression (GATA-1(low) mice). Blood. 2002;100(4):1123-1132.

16. Le Bousse-Kerdilès MC, Martyré MC; French INSERM research network on idiopathic myelofibrosis. Involvement of the fibrogenic cytokines, TGF-beta and bFGF, in the pathogenesis of idiopathic myelofibrosis. Pathol Biol (Paris). 2001;49(2):153-157.

17. Reilly JT. Pathogenesis of idiopathic myelofibrosis: role of growth factors. J Clin Pathol. 1992;45(6):461-464.

18. Chagraoui H, Komura E, Tulliez M, Giraudier S, Vainchenker W, Wendling F. Prominent role of TGF-beta 1 in thrombopoietin-induced myelofibrosis in mice. Blood. 2002;100(10):3495-3503.

19. Jacobson RJ, Salo A, Fialkow PJ. Agnogenic myeloid metaplasia: a clonal proliferation of hematopoietic stem cells with secondary myelofibrosis. Blood. 1978;51(2):189-194.

20. Tefferi A. Myelofibrosis with myeloid metaplasia. $N$ Engl J Med. 2000;342(17):1255-1265.

21. Reeder TL, Bailey RJ, Dewald GW, Tefferi A. Both B and T lymphocytes may be clonally involved in myelofibrosis with myeloid metaplasia. Blood. 2003;101(5):1981-1983.

22. Ihle JN, Kerr IM. Jaks and Stats in signaling by the cytokine receptor superfamily. Trends Genet. 1995;11(2):69-74.

23. Rawlings JS, Rosler KM, Harrison DA. The JAK/STAT signaling pathway. J Cell Sci. 2004;117(Pt 8):1281-1283.

24. Drachman JG, Griffin JD, Kaushansky K. The c-Mpl ligand (thrombopoietin) stimulates tyrosine phosphorylation of Jak2, Shc, and c-Mpl. J Biol Chem. 1995;270(10):4979-4982.

25. Neubauer H, Cumano A, Muller M, Wu H, Huffstadt U, Pfeffer K. Jak2 deficiency defines an essential developmental checkpoint in definitive hematopoiesis. Cell. 1998;93(3):397-409.

26. Parganas E, Wang D, Stravopodis D, et al. Jak2 is essential for signaling through a variety of cytokine receptors. Cell. 1998;93(3):385-395.

27. Radosevic N, Winterstein D, Keller JR, Neubauer H, Pfeffer K, Linnekin D. JAK2 contributes to the intrinsic capacity of primary hematopoietic cells to respond to stem cell factor. Exp Hematol. 2004;32(2):149-156.

28. Silvennoinen O, Witthuhn BA, Quelle FW, Cleveland JL, Yi T, Ihle JN. Structure of the murine Jak2 protein-tyrosine kinase and its role in interleukin 3 signal transduction. Proc Natl Acad Sci U S A. 1993;90(18):8429-8433.

29. Witthuhn BA, Quelle FW, Silvennoinen O, et al. JAK2 associates with the erythropoietin receptor and is tyrosine phosphorylated and activated following stimulation with erythropoietin. Cell. 1993;74(2): 227-236.

30. Quintás-Cardama A, Vaddi K, Liu P, et al. Preclinical characterization of the selective JAK1/2 inhibitor INCB018424: therapeutic implications for the treatment of myeloproliferative neoplasms. Blood. 2010;115(15): 3109-3117. 
31. Pikman Y, Lee BH, Mercher T, et al. MPLW515L is a novel somatic activating mutation in myelofibrosis with myeloid metaplasia. PLoS Med. 2006;3(7):e270.

32. Pardanani AD, Levine RL, Lasho T, et al. MPL515 mutations in myeloproliferative and other myeloid disorders: a study of 1182 patients. Blood. 2006;108(10):3472-3476.

33. Oh ST, Simonds EF, Jones C, et al. Novel mutations in the inhibitory adaptor protein LNK drive JAK-STAT signaling in patients with myeloproliferative neoplasms. Blood. 2010;116(6):988-992.

34. Grand FH, Hidalgo-Curtis CE, Ernst T, et al. Frequent CBL mutations associated with $11 \mathrm{q}$ acquired uniparental disomy in myeloproliferative neoplasms. Blood. 2009;113(24):6182-6192.

35. Barbui T, Barosi G, Birgegard G, et al. Philadelphia-negative classical myeloproliferative neoplasms: critical concepts and management recommendations from European LeukemiaNet. J Clin Oncol. 2011;29(6):761-770.

36. Samuelson S, Sandmaier BM, Heslop HE, et al. Allogeneic haematopoietic cell transplantation for myelofibrosis in 30 patients 60-78 years of age. Br J Haematol. 2011;153(1):76-82.

37. Löfvenberg E, Wahlin A. Management of polycythaemia vera, essential thrombocythaemia and myelofibrosis with hydroxyurea. Eur $J$ Haematol. 1988;41(4):375-381.

38. Martínez-Trillos A, Gaya A, Maffioli M, et al. Efficacy and tolerability of hydroxyurea in the treatment of the hyperproliferative manifestations of myelofibrosis: results in 40 patients. Ann Hematol. 2010;89(12):1233-1237.

39. Steurer M, Gastl G, Jedrzejczak WW, et al. Anagrelide for thrombocytosis in myeloproliferative disorders: a prospective study to assess efficacy and adverse event profile. Cancer. 2004;101(10):2239-2246.

40. Birgegard G, Bjorkholm M, Kutti J, et al. Adverse effects and benefits of two years of anagrelide treatment for thrombocythemia in chronic myeloproliferative disorders. Haematologica. 2004;89(5):520-527.

41. Sirhan S, Lasho TL, Hanson CA, Mesa RA, Pardanani A, Tefferi A. The presence of JAK2V617F in primary myelofibrosis or its allele burden in polycythemia vera predicts chemosensitivity to hydroxyurea. $\mathrm{Am} \mathrm{J}$ Hematol. 2008;83(5):363-365.

42. Mesa RA, Nagorney DS, Schwager S, Allred J, Tefferi A. Palliative goals, patient selection, and perioperative platelet management: outcomes and lessons from 3 decades of splenectomy for myelofibrosis with myeloid metaplasia at the Mayo Clinic. Cancer. 2006;107(2):361-370.

43. Elliott MA, Chen MG, Silverstein MN, Tefferi A. Splenic irradiation for symptomatic splenomegaly associated with myelofibrosis with myeloid metaplasia. Br J Haematol. 1998;103(2):505-511.

44. Besa EC, Nowell PC, Geller NL, Gardner FH. Analysis of the androgen response of 23 patients with agnogenic myeloid metaplasia: the value of chromosomal studies in predicting response and survival. Cancer. 1982;49(2):308-313.

45. Shimoda K, Shide K, Kamezaki K, et al. The effect of anabolic steroids on anemia in myelofibrosis with myeloid metaplasia: retrospective analysis of 39 patients in Japan. Int J Hematol. 2007;85(4): 338-343.

46. Cervantes F, Alvarez-Larrán A, Domingo A, Arellano-Rodrigo E, Montserrat E. Efficacy and tolerability of danazol as a treatment for the anaemia of myelofibrosis with myeloid metaplasia: long-term results in 30 patients. Br J Haematol. 2005;129(6):771-775.

47. Merup M, Kutti J, Birgergård G, et al. Negligible clinical effects of thalidomide in patients with myelofibrosis with myeloid metaplasia. Med Oncol. 2002;19(2):79-86.

48. Barosi G, Elliott M, Canepa L, et al. Thalidomide in myelofibrosis with myeloid metaplasia: a pooled-analysis of individual patient data from five studies. Leuk Lymphoma. 2002;43(12):2301-2307.

49. Mesa RA, Elliott MA, Schroeder G, Tefferi A. Durable responses to thalidomide-based drug therapy for myelofibrosis with myeloid metaplasia. Mayo Clin Proc. 2004;79(7):883-889.

50. Abgrall JF, Guibaud I, Bastie JN, et al. Thalidomide versus placebo in myeloid metaplasia with myelofibrosis: a prospective, randomized, double-blind, multicenter study. Haematologica. 2006;91(8):1027-1032.
51. Thomas DA, Giles FJ, Albitar M, et al. Thalidomide therapy for myelofibrosis with myeloid metaplasia. Cancer. 2006;106(9):1974-1984.

52. Mesa RA, Steensma DP, Pardanani A, et al. A phase 2 trial of combination low-dose thalidomide and prednisone for the treatment of myelofibrosis with myeloid metaplasia. Blood. 2003;101(7):2534-2541.

53. Jabbour E, Thomas D, Kantarjian H, et al. Comparison of thalidomide and lenalidomide as therapy for myelofibrosis. Blood. 2011;118(4):899-902.

54. Silverstein MN, Gomes MR, ReMine WH, Elveback LR. Agnogenic myeloid metaplasia. Natural history and treatment. Arch Intern Med. 1967;120(5):546-550.

55. Barosi G. Myelofibrosis with myeloid metaplasia: diagnostic definition and prognostic classification for clinical studies and treatment guidelines. J Clin Oncol. 1999;17(9):2954-2970.

56. Kralovics R, Passamonti F, Buser AS, et al. A gain-of-function mutation of JAK2 in myeloproliferative disorders. $N$ Engl J Med. 2005;352(17):1779-1790

57. James C, Ugo V, Le Couèdic JP, et al. A unique clonal JAK2 mutation leading to constitutive signalling causes polycythaemia vera. Nature. 2005;434(7037):1144-1148.

58. Levine RL, Wadleigh M, Cools $\mathrm{J}$, et al. Activating mutation in the tyrosine kinase JAK2 in polycythemia vera, essential thrombocythemia, and myeloid metaplasia with myelofibrosis. Cancer Cell. 2005; 7(4):387-397.

59. Baxter EJ, Scott LM, Campbell PJ, et al. Acquired mutation of the tyrosine kinase JAK2 in human myeloproliferative disorders. Lancet. 2005;365(9464):1054-1061.

60. Quintàs-Cardama A, Kantarjian H, Cortes J, Verstovsek S. Janus kinase inhibitors for the treatment of myeloproliferative neoplasias and beyond. Nat Rev Drug Discov. 2011;10(2):127-140.

61. Hedvat M, Huszar D, Herrmann A, et al. The JAK2 inhibitor AZD1480 potently blocks Stat 3 signaling and oncogenesis in solid tumors. Cancer Cell. 2009;16(6):487-497.

62. Tyner JW, Bumm TG, Deininger J, et al. CYT387, a novel JAK2 inhibitor, induces hematologic responses and normalizes inflammatory cytokines in murine myeloproliferative neoplasms. Blood. 2010;115(25):5232-5240.

63. Verstovsek S, Odenike O, Scott B, et al. Phase I dose-escalation trial of SB1518, a novel JAK2/FLT3 inhibitor, in acute and chronic myeloid diseases, including primary or post-essential thrombocythemia/ polycythemia vera myelofibrosis [abstract]. Blood. 2009;114(22):3905.

64. US Food and Drug Administration. Silver Spring: US Food and Drug Administration [updated November 16, 2001; cited November 18, 2011]. Available from: http://www.fda.gov/NewsEvents/Newsroom/ PressAnnouncements/ucm280102.htm. Accessed December 21, 2011.

65. Manshouri T, Estrov Z, Knez L, Creighton C, Kantarjian H, Verstovsek $\mathrm{S}$. Bone marrow stroma-mediated paracrine inhibition of ruxolitinib (INCB018424)-induced apoptosis of JAK2V617F mutated cells: protective effect of myeloproliferative neoplasm patient-derived but not healthy donnor-derived stroma [abstract]. Haematologica. 2011;96 (6 Suppl 2):0316.

66. Deshpande A, Reddy MM, Schade GO, et al. Kinase domain mutations confer resistance to novel inhibitors targeting JAK2V617F in myeloproliferative neoplasms. Leukemia. September 16, 2011. [Epub ahead of print.]

67. Shilling AD, Nedza FM, Emm T, et al. Metabolism, excretion, and pharmacokinetics of [14C]INCB018424, a selective Janus tyrosine kinase 1/2 inhibitor, in humans. Drug Metab Dispos. 2010;38(11):2023-2031.

68. Shi JG, Chen X, McGee RF, et al. The pharmacokinetics, pharmacodynamics, and safety of orally dosed INCB018424 phosphate in healthy volunteers. J Clin Pharmacol. 2011;51(12):1644-1654.

69. Chen X, Shi J, McGee R, et al. The effect of various degrees of hepatic dysfunction on the pharmacokinetics of INCB018424 [abstract]. Clin Pharmacol Ther. 2010;87(2 Suppl 1):PIII-P59.

70. Jakafi [package insert]. Wilmington DE: Incyte Corporation; 2011. 
71. Shi JG, Chen X, Emm T, et al. The effect of CYP3A4 inhibition or induction on the pharmacokinetics and pharmacodynamics of orally administered ruxolitinib (INCB018424 phosphate) in healthy volunteers. J Clin Pharmacol. May 20, 2011. [Epub ahead of print.]

72. Ostojic A, Vrhovac R, Verstovsek S. Ruxolitinib: a new JAK1/2 inhibitor that offers promising options for treatment of myelofibrosis. Future Oncol. 2011;7(9):1035-1043.

73. Ostojic A, Vrhovac R, Verstovsek S. Ruxolitinib for the treatment of myelofibrosis. Drugs Today (Barc). 2011;47(11):817-829.

74. Verstovsek S, Kantarjian H, Mesa RA, et al. Safety and efficacy of INCB018424, a JAK1 and JAK2 inhibitor, in myelofibrosis. $N$ Engl J Med. 2010;363(12):1117-1127.

75. Harrison CN, Kiladjian J, Al-Ali HK, et al. Results of a randomized study of the JAK inhibitor ruxolitinib (INC424) versus best available therapy (BAT) in primary myelofibrosis (PMF), post-polycythemia vera-myelofibrosis (PPV-MF) or post-essential thrombocythemiamyelofibrosis (PET-MF) [abstract]. J Clin Oncol. 2011; 29(15 Suppl 1):LBA6501.

76. Verstovsek S, Mesa R, Gotlib J, Levy R, Gupta V. Results of COMFORT-I, a randomized double-blind phase III trial of JAK 1/2 inhibitor INCB18424 (424) versus placebo (PB) for patients with myelofibrosis (MF) [abstract]. J Clin Oncol. 2011;29(15 Suppl 1):6500.

77. Verstovsek S, Mesa R, Gotlib J, et al. Results of COMFORT-I, a randomized, double-blind phase III trial of the JAK1 and JAK2 inhibitor ruxolitinib (INCB018424) versus placebo for patients with myelofibrosis [abstract]. Haematologica. 2011;96(6 Suppl 2):0505.

78. Tefferi A, Litzow MR, Pardanani A. Long-term outcome of treatment with ruxolitinib in myelofibrosis. N Engl J Med. 2011;365(15): 1455-1457.

79. Tefferi A, Pardanani A. Serious adverse events during ruxolitinib treatment discontinuation in patients with myelofibrosis. Mayo Clin Proc. 2011;86(12):1188-1191.

80. Dupriez B, Morel P, Demory JL, et al. Prognostic factors in agnogenic myeloid metaplasia: a report on 195 cases with a new scoring system. Blood. 1996;88(3):1013-1018.

81. Mesa R, Kantarjian H, Tefferi A, et al. Functional assessment of performance status in patients with myelofibrosis (MF): Utility and feasibility of the 6-minute walk test (6MWT) [abstract]. J Clin Oncol. 2009;96(Supp1 15s):7083.

82. Verstovsek S, Estrov Z, Cortes J, et al. The MD Anderson Cancer Center (MDACC) experience with ruxolitinib, an oral JAK1 and JAK2 inhibitor, in myelofibrosis: long-term follow-up outcomes of 107 patients from a phase I/II study [abstract]. Blood. 2011;118(21):3851.
83. Verstovsek S, Kantarjian H, Estrov Z, et al. Comparison of outcomes of advanced myelofibrosis patients treated with ruxolitinib (INCB018424) to those of a historical control group: survival advantage of ruxolitinib therapy [abstract]. Blood. 2011;118(21):793.

84. Mesa RA, Kantarjian H, Tefferi A, et al. Evaluating the serial use of the Myelofibrosis Symptom Assessment Form for measuring symptomatic improvement: performance in 87 myelofibrosis patients on a JAK1 and JAK2 inhibitor (INCB018424) clinical trial. Cancer. 2011;117(21):4869-4877.

85. Verstovsek S, Mesa R, Gotlib J, et al. Consistent benefit of ruxolitinib over placebo in spleen volume reduction and symptom improvement across subgroups and overall survival advantage: results from COMFORT-I [abstract]. Blood. 2011;118(21):278.

86. Aaronson NK, Ahmedzai S, Bergman B, et al. The European Organization for Research and Treatment of Cancer QLQ-C30: a quality-of-life instrument for use in international clinical trials in oncology. J Natl Cancer Inst. 1993;85(5):365-376.

87. Mesa R, Kantarjian H, Shields A, et al. Results using the Modified Myelofibrosis Symptom Assessment Form (MFSAF v2.0) in COMFORT-I: a randomized, double-blind phase III trial of JAK1/2 inhibitor ruxolitinib vs placebo in myelofibrosis (MF) [abstract]. Haematologica. 2011;96(6 Suppl 2):0912.

88. Mesa R, Gotlib J, Gupta V, et al. Associations between improvements in myelofibrosis (MF) symptoms and quality of life measures with splenomegaly reduction in COMFORT-I: a randomized, double-blind, phase III trial of the JAK1 and JAK2 inhibitor ruxolitinib versus placebo in patients with MF [abstract]. Blood. 2011;118(21):3842.

89. Harrison C, Kiladjian J, Gisslinger H, et al. Ruxolitinib provides reductions in splenomegaly across subgroups: an analysis of spleen response in the COMFORT-II study [abstract]. Blood. 2011;118(21):279.

90. Harrison C, Kiladjian J, Kathrin Al-Ali H, et al. Health-related quality of life and symptoms in myelofibrosis patients treated with ruxolitinib versus best available therapy [abstract]. Blood. 2011;118(21):795.

91. Cella D, Webster K, Cashy J, et al. Development of a measure of health-related quality of life for non-Hodgkin's lymphoma clinical research: the Functional Assessment of Cancer Therapy - Lymphoma (FACT-Lym) [abstract]. Blood. 2005;106(11):750.

92. Mesa R, Verstovsek S, Cervantes F, et al. Comparison of the efficacy of placebo and best available therapy for the treatment of myelofibrosis in the COMFORT studies [abstract]. Blood. 2011;118(21):1753.
Therapeutics and Clinical Risk Management

\section{Publish your work in this journal}

Therapeutics and Clinical Risk Management is an international, peerreviewed journal of clinical therapeutics and risk management, focusing on concise rapid reporting of clinical studies in all therapeutic areas, outcomes, safety, and programs for the effective, safe, and sustained use of medicines. This journal is indexed on PubMed Central, CAS,

\section{Dovepress}

EMBase, Scopus and the Elsevier Bibliographic databases. The manuscript management system is completely online and includes a very quick and fair peer-review system, which is all easy to use. Visit http://www.dovepress.com/testimonials.php to read real quotes from published authors. 